Check for updates

Cite this: RSC Adv., 2017, 7, 53247

\title{
Synthesis and characterization of calcium-induced peanut protein isolate nanoparticles
}

\author{
Aimin Shi, $\uparrow^{a}$ Xue Chen, $\uparrow^{\mathrm{ab}} \mathrm{Li} \mathrm{Liu}{ }^{\mathrm{a}}$ Hui Hu, ${ }^{a}$ Hongzhi Liu, ${ }^{a}$ Qiang Wang (D) *a \\ and Dominic Agyei (D)
}

A convenient and green synthetic route using calcium ion induction was first used to prepare peanut protein isolate (PPI) nanoparticles. Through dynamic light scattering (DLS) and transmission electron microscopy (TEM), the role of each procedure in the formation of nanoparticles was systematically investigated by means of particle size, size distribution, and morphology observation. The size of the obtained nanoparticles ranged from 80 to $140 \mathrm{~nm}$, and they exhibited a uniform size distribution and spherical shape. After dry processing, PPI nanoparticles still display a good state in terms of size and morphology. Stability test results indicated that PPI nanoparticles have good thermal stability, gastrointestinal $\mathrm{pH}$ stability, dilution stability and storage stability. In particular, these nanoparticles still have good stability with their concentration diluted to $0.05 \mathrm{mg} \mathrm{mL}^{-1}$ while they can be stored for up to 60 days with particle sizes still below $120 \mathrm{~nm}$ at room temperature. All these features endow PPI nanoparticles with great potential in the delivery of bioactive compounds.

Received 20th July 2017

Accepted 8th November 2017

DOI: $10.1039 / \mathrm{c} 7 \mathrm{ra} 07987 \mathrm{~g}$

rsc.li/rsc-advances are relatively few. At present, the plant proteins which have been applied in the preparation of nanoparticles are only silk, soy protein isolates or zein etc. ${ }^{7,17,18}$ Peanut protein is a highly nutritious vegetable protein resource, ranking no. 3 of plant protein sources in the world, accounting for $11 \%$ of total protein. ${ }^{19}$ However, its application for the preparation of nanoparticle, carrying and delivery peanut bioactive compounds, is still blank.

Nowadays, many physic, chemical and biologic methods have been developed for the preparation of protein nanoparticle including desolvation, ${ }^{20}$ hydrolysis, ${ }^{21} \mathrm{pH}$-coacervation, ${ }^{22}$ selfassembly $^{23}$ and emulsification dispersion. ${ }^{24}$ Whereas, these methods still have some disadvantage with complicated process, sophisticated control and using of organic reagents. And so, such ionic induced method, which is easier, greener processing and suitable for food processing, has much more potential for natural protein nanoparticles and is rarely studied.

In this study, we report a calcium-induced method first applying in preparation of peanut protein isolate nanoparticle. The nanoparticles were characterized by the particle size, size distribution, and morphology. And the effects of spray drying and freeze drying on the physiochemical properties of peanut protein nanoparticles were analyzed. In addition, the thermal stability, gastrointestinal $\mathrm{pH}$ stability, dilution stability and storage stability of PPI nanoparticles were evaluated.

\section{Materials and methods}

\subsection{Materials and instrument}

PPI was made by laboratory according to previous literature method. ${ }^{19}$ Anhydrous calcium chloride, sodium hydroxide and 
hydrochloric acid were purchased from Sinopharm Chemical Reagent Co., Ltd.

90-4 digital temperature control magnetic stirrer, Zhenrong Scientific Instrument Co., Ltd. Shanghai; DK-S24 electro thermal constant temperature water bath, Jinghong Experimental Equipment Co., Ltd., Shanghai; Nano laser particle size analyzer, Malvern Instrument Co., Ltd., Britain; H-7500 transmission electron microscopy, Hitachi, Japan.

\subsection{Preparation of PPI nanoparticle}

Peanut protein powder was hydrated in deionized water $\left(6 \mathrm{mg} \mathrm{mL}^{-1}\right)$ and stirred for $15 \mathrm{~min}$ at room temperature. Then there are four steps for the preparation. (1) Using 0.1 M NaOH to prepare different peanut protein isolate suspension with $\mathrm{pH}$ of 8, 9, 10, 11 and 12, separately. (2) Keeping these five suspensions at $85{ }^{\circ} \mathrm{C}$ for $30 \mathrm{~min}$ in tightly closed tubes using a waters bath. (3) Then cooling to room temperature and adjusting the $\mathrm{pH}$ of these suspensions back to 7 using $0.1 \mathrm{M} \mathrm{HCl}$. (4) Adding $\mathrm{CaCl}_{2}$ with the concentration of $2.5,3.5,5.0,6.5$ and $7.5 \mathrm{mM}$ into these suspension to induce particle formation. The final protein concentration was diluted to $3 \mathrm{mg} \mathrm{mL} \mathrm{m}^{-1}$ using deionized water for further analyzation. The prepared suspensions were stored at room temperature overnight to make the formation of PPI nanoparticle.

\subsection{Morphology characteristics of PPI nanoparticles}

The size and polydispersity index of the nanoparticles were measured at $25^{\circ} \mathrm{C}$ by dynamic light scattering using a Zetasizer NanoS. Their suspensions were diluted in deionized water to a suitable concentration before analysis.

The morphology of the PPI solution without calcium and PPI nanoparticles was observed by $\mathrm{H}-7500$ Transmission Electron Microscope $($ TEM $)$ in two resolutions $(\times 10000$ and $\times 50000)$. For sample preparation, one drop of the prepared suspensions was placed on copper net coated with polyvinyl formal membrane. The copper mesh was placed in the 2-3 min to make the molecular aggregates deposited on the surface of the network, and then the extra suspensions were blotted with filter paper. $2 \%$ uranyl-acetate solution was added on the copper mesh to negative staining for nanoparticles, and used filter paper to blot the extra dye liquor when staining complete. The samples were air dried before imaging.

\subsection{Drying characteristics of the nanoparticles}

The PPI nanoparticle suspension was treated by vacuum freeze drying and sprays drying, respectively. And the effect of particle size and PDI was compared in the two drying methods. The morphological changes of peanut protein nanoparticles were observed by transmission electron microscope. In addition, the effects of different spray drying temperature at $145^{\circ} \mathrm{C}, 150{ }^{\circ} \mathrm{C}, 155^{\circ} \mathrm{C}, 160{ }^{\circ} \mathrm{C}, 165^{\circ} \mathrm{C}, 170^{\circ} \mathrm{C}$ and $140{ }^{\circ} \mathrm{C}$ on the particle size and morphology of the nanoparticles were investigated.

\subsection{Stability analysis of PPI nanoparticles}

2.5.1 Thermal stability. The PPI nanoparticles suspension was respectively treated in the thermostatic bath at $74{ }^{\circ} \mathrm{C}, 20 \mathrm{~s}$ (Pasteur sterilization) and boiling water bath for $5 \mathrm{~min}$. Then the particle size and distribution of the nanoparticles were measured by laser particle size analyzer.

2.5.2 Gastrointestinal $\mathbf{p H}$ stability. The influence of gastrointestinal pH on PPI nanoparticle stability was evaluated by suspending nanoparticles in simulated gastric fluid ( $\mathrm{pH} 1.2)$ or simulated intestinal fluid $(\mathrm{pH} 7.4)$ without enzyme. The nanoparticle solution and simulated intestinal fluid or simulated intestinal fluid was mixed with the same volume.
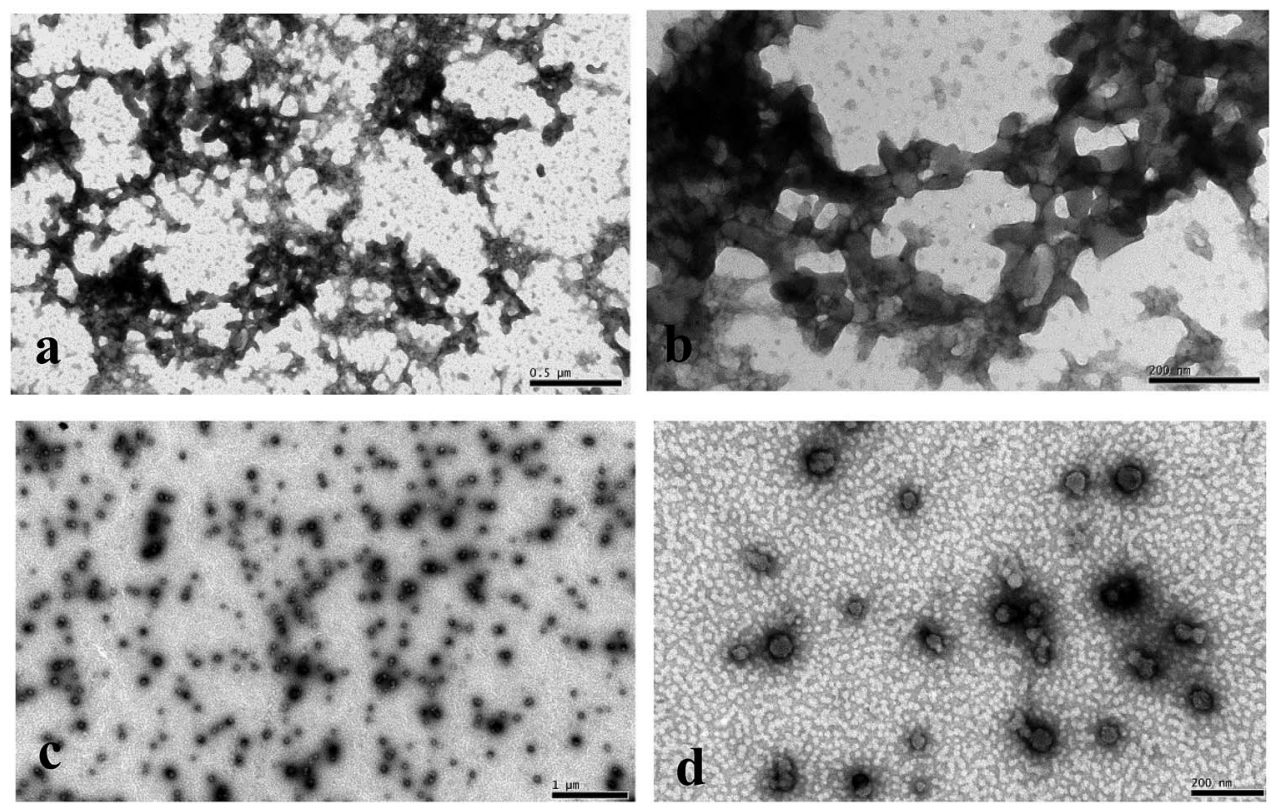

Fig. 1 The TEM photos of the PPI solution without calcium (a, b) and PPI nanoparticles (c, d). 
2.5.3 Dilution stability. The concentration of nanoparticle samples was diluted with distilled water with the same $\mathrm{pH}$ value to $0.5 \mathrm{mg} \mathrm{ml}^{-1}, 0.1 \mathrm{mg} \mathrm{ml}^{-1}, 0.05 \mathrm{mg} \mathrm{ml}^{-1}, 0.01 \mathrm{mg} \mathrm{ml}^{-1}$, $0.0025 \mathrm{mg} \mathrm{ml}^{-1}$ and $0.0001 \mathrm{mg} \mathrm{ml}^{-1}$. And then the particle size and distribution of dilution solution were determined by laser particle size analyzer.

2.5.4 Long-term storage stability. The storage stability of PPI nanoparticles was investigated by measuring particle size and distribution after storage at $4{ }^{\circ} \mathrm{C}$ and room temperature for $5,10,15,20,25,30,40,50$ and 60 days respectively.

\subsection{Statistical analysis}

All experiments were performed at least in triplicate. Results were expressed in tables as mean \pm standard deviation. Error bars on figures represented standard deviations.

\section{Results and discussion}

\subsection{Nanoparticle characterization}

From our results, we success obtained PPI nanoparticles with relative ideal size and narrow size distribution. The main mechanism was illustrated in Fig. 1. As described in Section 2.2, peanut protein was first treated with alkali $(0.1 \mathrm{M} \mathrm{NaOH})$ at $85^{\circ} \mathrm{C}$. In this processing, peanut protein was fully hydrated and unfolding..$^{25-27}$ And the quarternary structure of protein was destroyed, which resulting into a good dissolution characteristic after adjusting the $\mathrm{pH}$ to $7.0 .^{27,28}$ In such suspension condition, the surface charge of PPI fractions was negative. And then the addition of calcium ion was a trigger and interference for system charge re-balance and PPI protein was tending to gather together around calcium ion to realize the electric

Table 1 Effect of $\mathrm{pH}$ condition on the size of peanut protein isolates nanoparticles

\begin{tabular}{lllll}
\hline pH & 8 & 9 & 10 & 11 \\
Diameter $(\mathrm{nm})$ & $132 \pm 5$ & $106 \pm 1$ & $91 \pm 1$ & $89 \pm 1$ \\
PDI & $0.26 \pm 0.01$ & $0.35 \pm 0.01$ & $0.38 \pm 0.01$ & $0.40 \pm 0.02$
\end{tabular}

Table 2 Effect of $\mathrm{Ca}^{2+}$ concentration on the size of peanut protein isolates nanoparticles

\begin{tabular}{lllll}
\hline $\mathrm{Ca}^{2+}(\mathrm{mM})$ & 2.5 & 3.5 & 5.0 & 5.5 \\
Diameter $(\mathrm{nm})$ & $125 \pm 6$ & $95 \pm 1$ & $87 \pm 1$ & $92 \pm 2$ \\
PDI & $0.50 \pm 0.01$ & $0.50 \pm 0.01$ & $0.31 \pm 0.07$ & $0.25 \pm 0.01$
\end{tabular}

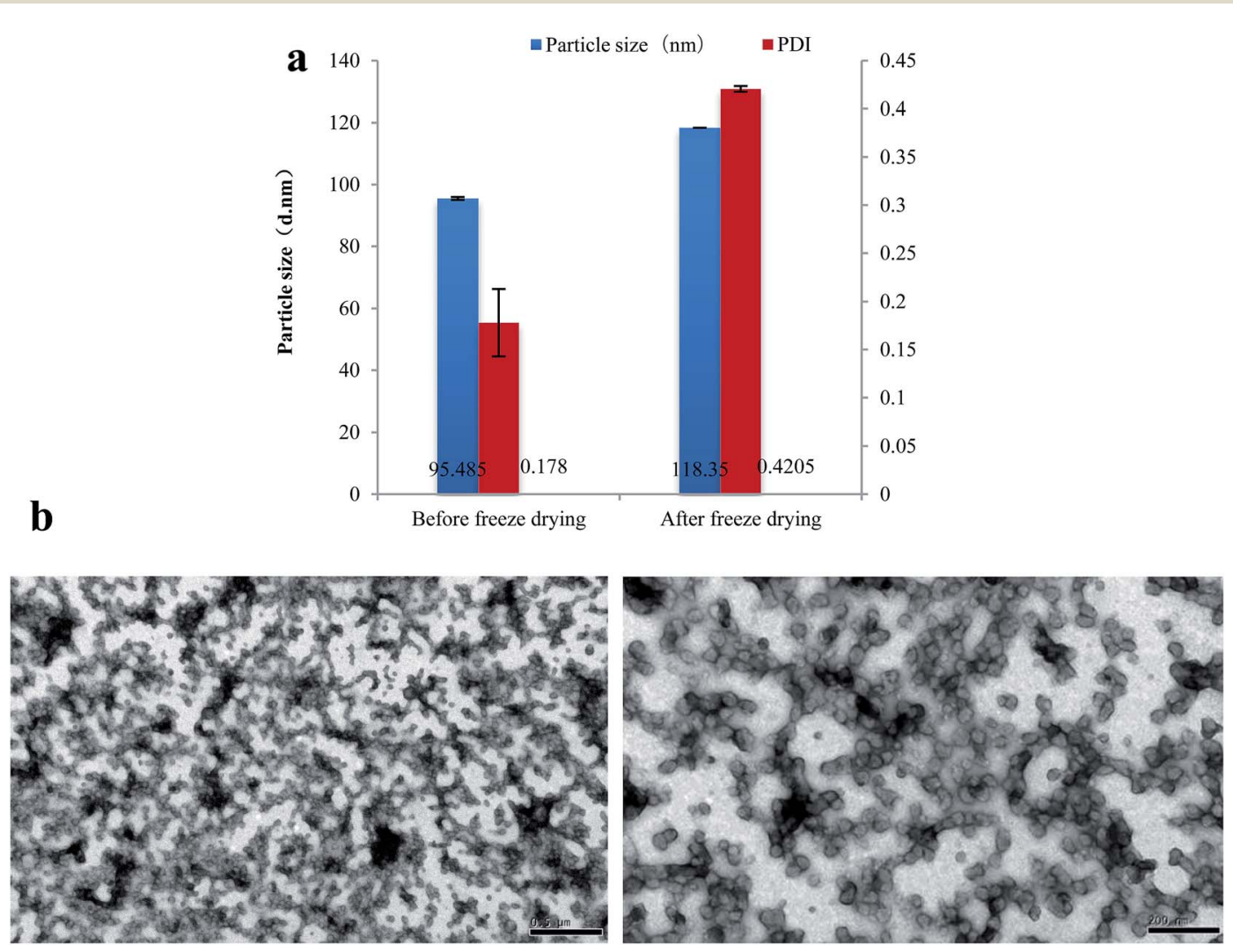

Fig. 2 Particle size and PDI of PPI nanoparticles after freeze drying (a), TEM photos of PPI nanoparticles after freeze drying (b). 
neutrality of whole suspension. Such theory can be used to explain the preparation of tofu and soybean protein nanoparticles. ${ }^{18,29}$

3.1.1 Particle size. The size of the PPI nanoparticles as influenced by solution $\mathrm{pH}$ and calcium concentrations, respectively can be observed from Tables 1 and 2. Particles with various sizes of $87-136 \mathrm{~nm}$ were obtained under the different preparation conditions, and the PdI of all the samples was ranged from 0.200 to 0.500 . This result indicates that the nanoparticles were achieved with good dispersibility and narrow particle size distribution. ${ }^{24}$

The solution $\mathrm{pH}$ has played an important role in determining PPI nanoparticle size. With the increase of the $\mathrm{pH}$ condition, the particle size of PPI nanoparticles was first decreased and then increased, and reached the minimum at $\mathrm{pH}$ 11 (Table 1). That may be because in the low pH (8), PPI structure was still well without fully unfolding and destroyed. During the calcium ion induction, large particle size could be found. With the increase of $\mathrm{pH}$ from 8 to 11, PPI was tending to more and more hydration, the interaction between subunits (protein quaternary structure) was gradually broken, and the size of PPI fractions was cut down. ${ }^{27,28}$ And finally, the size of PPI nanoparticles was decreased. However, the size was increased again when $\mathrm{pH}$ changed to 12 . That is possibly resulted from that the structure of polypeptide chains in PPI subunits was destroyed and fully stretched in suspension. ${ }^{26}$ Based on this condition, PPI nanoparticles show larger size (Table 2).

The other factor impacting nanoparticle size was calcium concentration. When the $\mathrm{CaCl}_{2}$ concentration was increased from 2.5 to $5 \mathrm{mM}$, the particle size decreased from 125.10 to $87.35 \mathrm{~nm}$, respectively. However, when the concentration of calcium continues to increase, the particle size increased to $111.60 \mathrm{~nm}$ (Table 2). The explanation for this may be that for fully hydrated protein, there would be a quantizable amount of $\mathrm{Ca}^{2+}$ for whole suspension. If the concentration was lower than this suitable amount, PPI segments would compete to interact with $\mathrm{Ca}^{2+}$, resulting into particle cluster. However, when the concentration was higher than this suitable amount, redundant $\mathrm{Ca}^{2+}$ could stay in the suspension and influence the surface charge of already formed PPI nanoparticle, generating

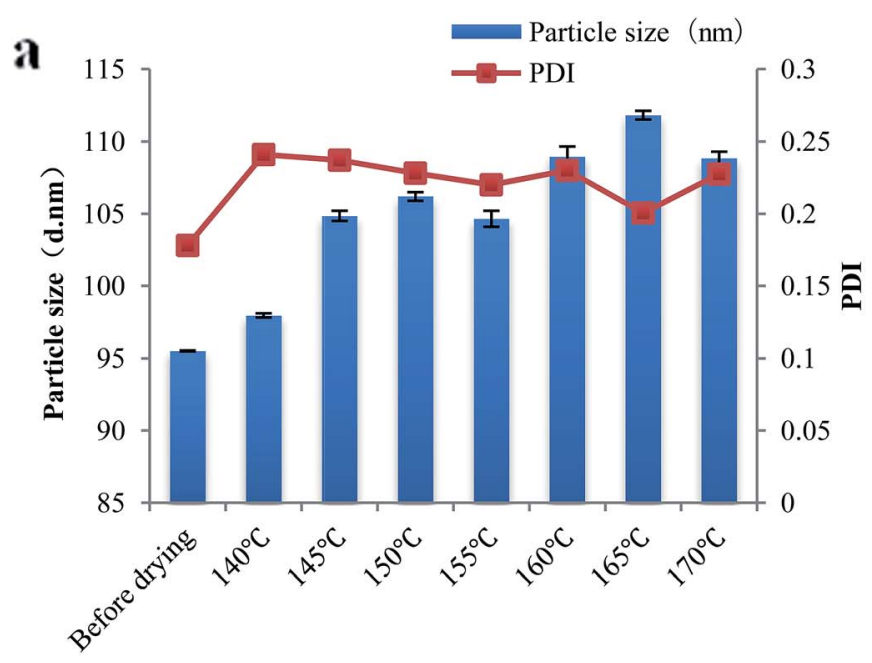

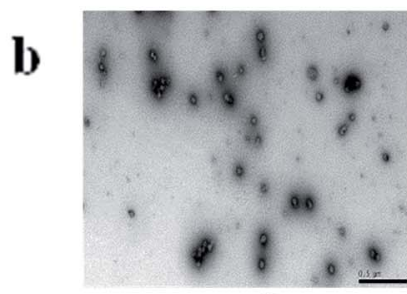

$140^{\circ} \mathrm{C}$

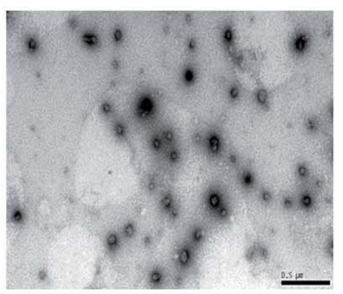

$145^{\circ} \mathrm{C}$

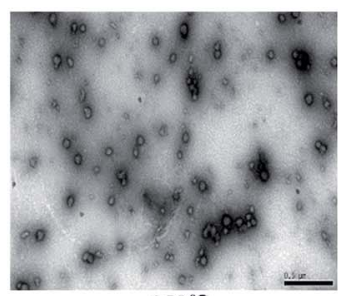

$150^{\circ} \mathrm{C}$

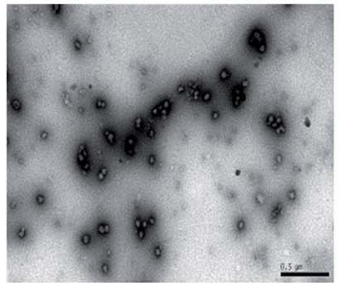

$155^{\circ} \mathrm{C}$

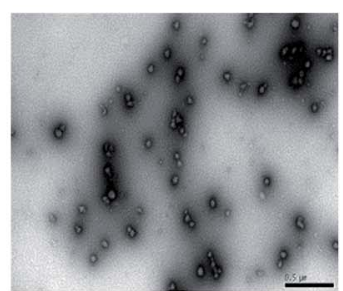

$160^{\circ} \mathrm{C}$

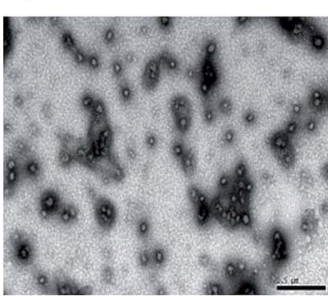

$165^{\circ} \mathrm{C}$

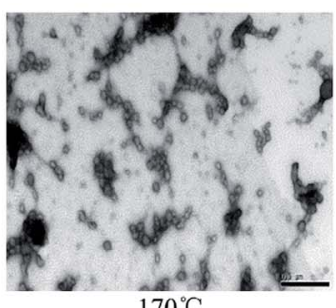

$170^{\circ} \mathrm{C}$

Fig. 3 Particle size and PDI of PPI nanoparticles after spray drying (a), TEM photos of PPI nanoparticles after spray drying (b). 
aggregates with larger size. ${ }^{18}$ Integrated above, the PPI nanoparticle with the minimum size was chosen for further characterization.

3.1.2 Nanoparticle morphology. The morphology of the PPI solution without calcium is shown in Fig. 1a and b, which confirmed that there is no nanoparticle formed. Whereas the PPI nanoparticles were successfully prepared upon the addition of calcium, Fig. 1c and d shows that the most of PPI nanoparticles have a good sphericity and dispersion, and the particle size ranges between $80 \mathrm{~nm}$ and $120 \mathrm{~nm}$. The result of Fig. 1 was in agreement that calcium can induce a nano-scale network formation of molecular chain segments from protein hydrolysate. ${ }^{18}$

\subsection{Drying characteristics of the nanoparticles}

Spray drying and vacuum freeze drying have been widely used in various fields due to its high efficiency, large output, short drying time and excellent product characteristics. ${ }^{30,31}$ In this study, spray drying and vacuum freeze drying were used to prepare the dry PPI nanoparticles, and the particle size, PDI and morphology of the nanoparticles were compared by the two drying methods.

Vacuum freeze drying is mainly adopts low temperature freezing first, and then make the water directly from a solid into a gas under the low vacuum or vacuum heating condition, finally get dry products. ${ }^{32}$ After freeze drying, the size and PDI of PPI nanoparticles have significant increased from $95.49 \mathrm{~nm}$ to $118.35 \mathrm{~nm}$ and from 0.19 to 0.42 (Fig. 2a) compared with Fig. 1c and $d$. But as we can see from Fig. $2 b$, their microcosmic shape was similar. And these results have showed a good consistency with the report ones, which illustrate that vacuum freeze drying can well maintain the microstructure of sample and especially suitable for nanoparticles. ${ }^{33}$

Spray drying is mainly referring to that the material pushed by high-pressure gas was through the atomizer and formed fine droplets, then under the high temperature environment of dryer, droplets would be evaporation and solid powder particles were obtained. Finally a cyclone separation device is used to obtain dry state products. ${ }^{34}$

As we can see from Fig. 3, the particle size, PdI and morphology of PPI nanoparticles after spray drying were shown. The particle size of nanoparticles increases slightly after spray drying at each inlet temperature, and it's less than $110 \mathrm{~nm}$. And the PdI is ranged from 0.2 to 0.25 , which suggests that after spray drying, the nanoparticles still have narrow particle size distribution (Fig. 3a). Fig. 3b showed the TEM photos of PPI nanoparticles after spray drying at different inlet temperature. With the increase of the inlet temperature, the aggregation of PPI nanoparticles is becoming more and more serious. This may be resulting from that high inlet temperature could lead to water evaporation and the interaction of PPI nanoparticles which was common in protein drying. ${ }^{35}$

In addition, from the results of vacuum freeze drying and spray drying, we can conclude that though drying processing would slightly result into the aggregation of PPI nanoparticle,

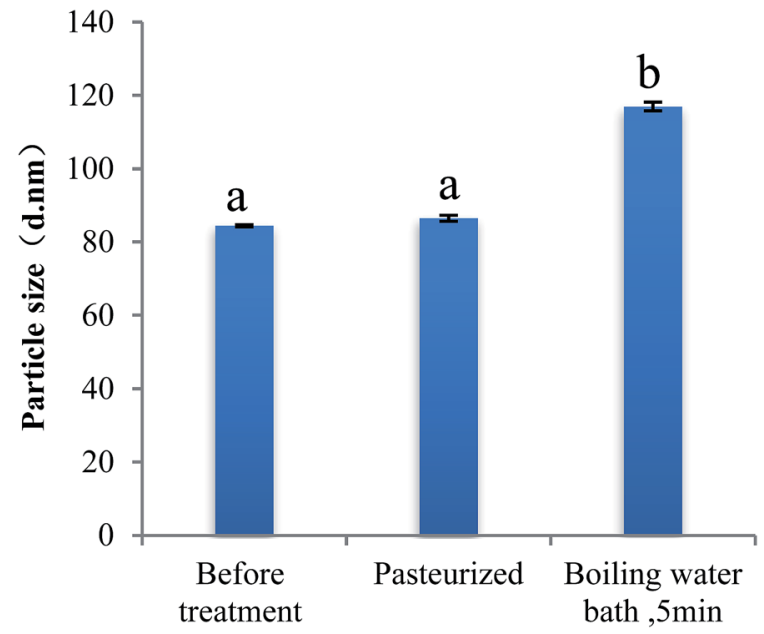

Fig. 4 Particle size of PPI nanoparticles after different heat treatment.

the particle size and PdI didn't increase much. And according to efficiency, cost and status of finally sample, spray drying under low inlet temperature will be suitable for further research and application.

\subsection{Nanoparticle stability}

3.3.1 Thermal stability of nanoparticles. The thermal stability of the PPI nanoparticles is shown in Fig. 4. Under the condition of the pasteurization $\left(74{ }^{\circ} \mathrm{C}, 20 \mathrm{~s}\right)$, the size of the PPI nanoparticles was not significantly changed. When the PPI nanoparticles were treated by boiling water bath for $5 \mathrm{~min}$, the size of the nanoparticles changed significantly, this may be due to particle aggregation occurred that caused by heating. ${ }^{36}$ However, after heating was applied, the particle size was still less than $200 \mathrm{~nm}$, it's proved that the PPI nanoparticles are still having good state after heat treatment, which displayed the good thermal stability of the PPI nanoparticles. And this result also suggests that heat process has no effect on the protein solubility which can be explained by the fully hydration and denaturation (quaternary structure was destroyed) of protein during PPI preparation.

3.3.2 Gastrointestinal pH stability of nanoparticles. As we can see from Fig. 5a and b, the particle size and distribution of PPI nanoparticles, respectively, as influenced by gastrointestinal $\mathrm{pH}$ conditions is shown. Under the condition of simulated intestinal fluid $\mathrm{pH}(\mathrm{pH}=7.4)$, the particle size of nanoparticles was slightly increased, and it has been expanded, which may be related to dilution, while the particle size has a significant increase under the condition of simulated gastric fluid $\mathrm{pH}$ $(\mathrm{pH}=1.2)$ (Fig. 5a). In addition, the particle size distribution of nanoparticles in the simulated gastric fluid was widened obviously (Fig. 5b). This may be caused by the nanoparticles was partial dissociation under the acid condition. ${ }^{37}$ Compared to the change of the particle size and distribution under the conditions of simulated gastrointestinal $\mathrm{pH}$, it can be seen that the stability of nanoparticles in the intestine was significantly higher than the stability in the stomach. 

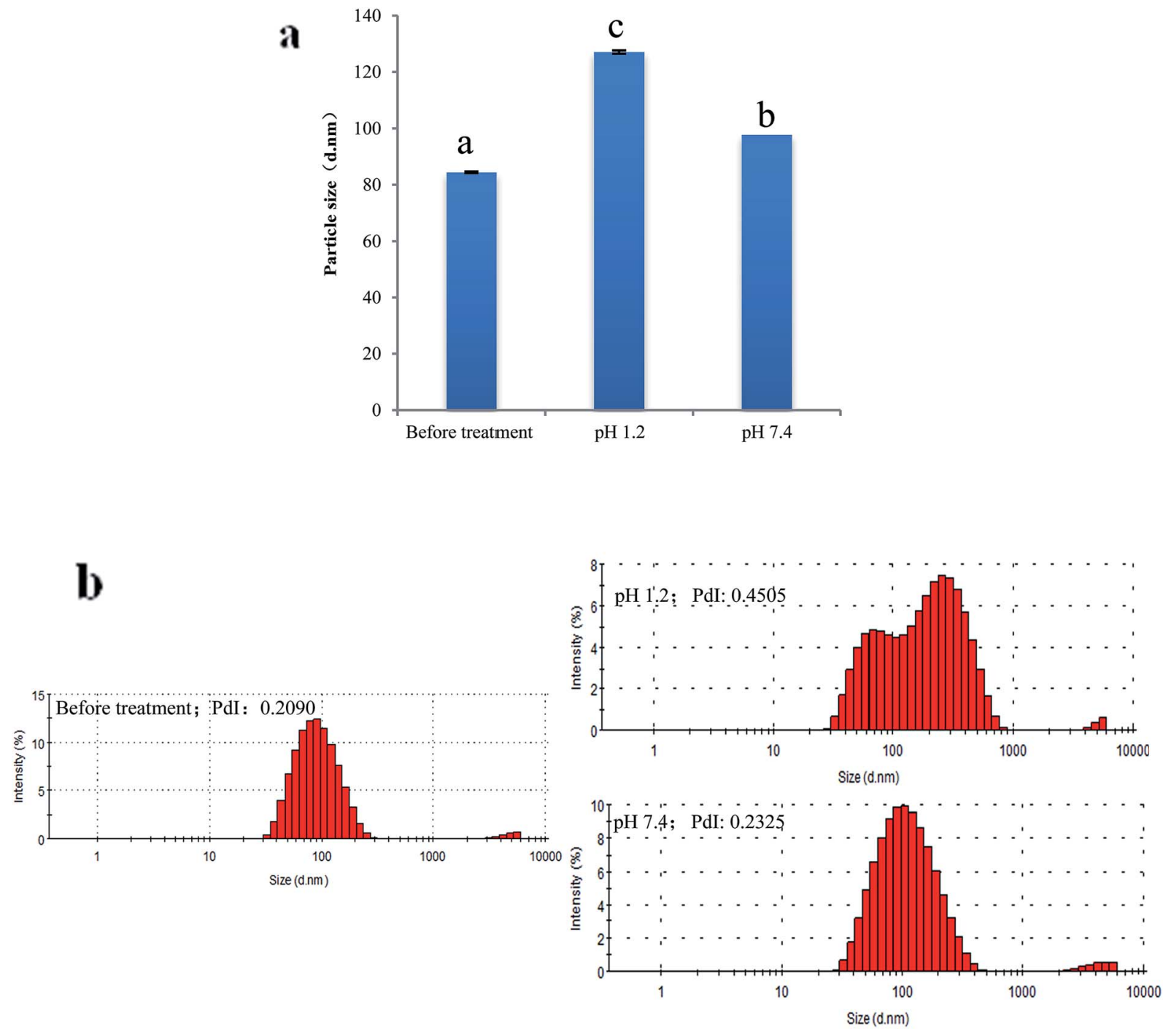

Fig. 5 Particle size (a) and distribution (b) of PPI nanoparticles in gastrointestinal pH value.

3.3.3 Dilution stability of nanoparticles. Dilution stability is one of the important evaluation indicators of nanoparticles' properties. In the actual application process, nanoparticles will face serious dilution when into the body, which would cause the destruction of nanoparticles. ${ }^{38}$

Fig. 6 presents the change of particle size and PdI of PPI nanoparticles in the continuous dilution. In the process of nanoparticle concentration was diluted from $1 \mathrm{mg} \mathrm{mL}{ }^{-1}$ to $0.05 \mathrm{mg} \mathrm{mL} \mathrm{m}^{-1}$, the particle size measured by dynamic light scattering was no significant change, this proves that the nanoparticles remained stable and did not dissociation. When the concentration of nanoparticles is below $0.05 \mathrm{mg} \mathrm{ml}^{-1}$, the nanoparticle size increases slightly but is significant, this may be due to the dissociation of the nanoparticles which caused by the decrease of the ion concentration, as well as the equilibrium of the system was broken.

3.3.4 Storage stability of nanoparticles. The storage stability of PPI nanoparticles was shown in Fig. 7. The PPI nanoparticle was placed at $4{ }^{\circ} \mathrm{C}$ and room temperature, then the particle size was measured at intervals, respectively. The results showed that the particle size of the PPI nanoparticles was remained stable in the 60 days of storage, and the size of particles was always below $120 \mathrm{~nm}$. In addition, the stability of

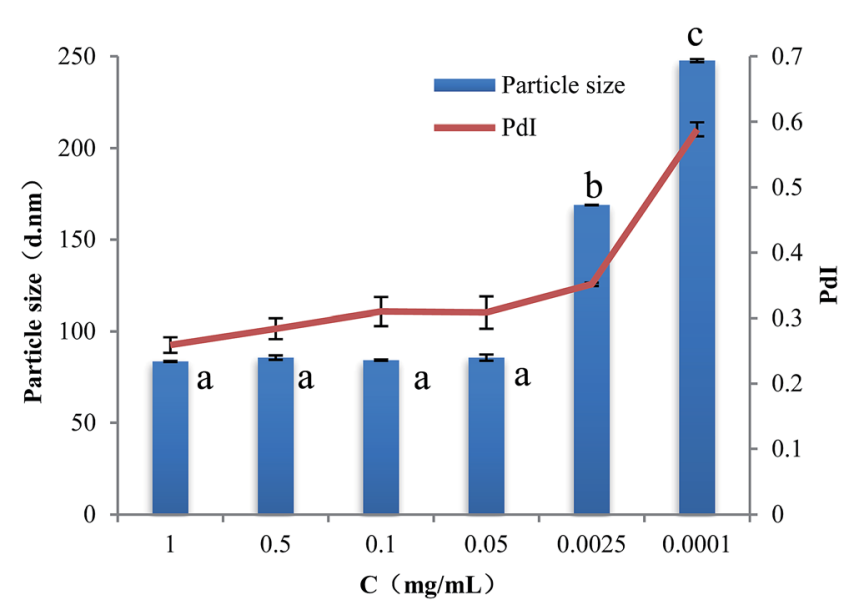

Fig. 6 Particle size and PDI of PPI nanoparticles after dilution. 


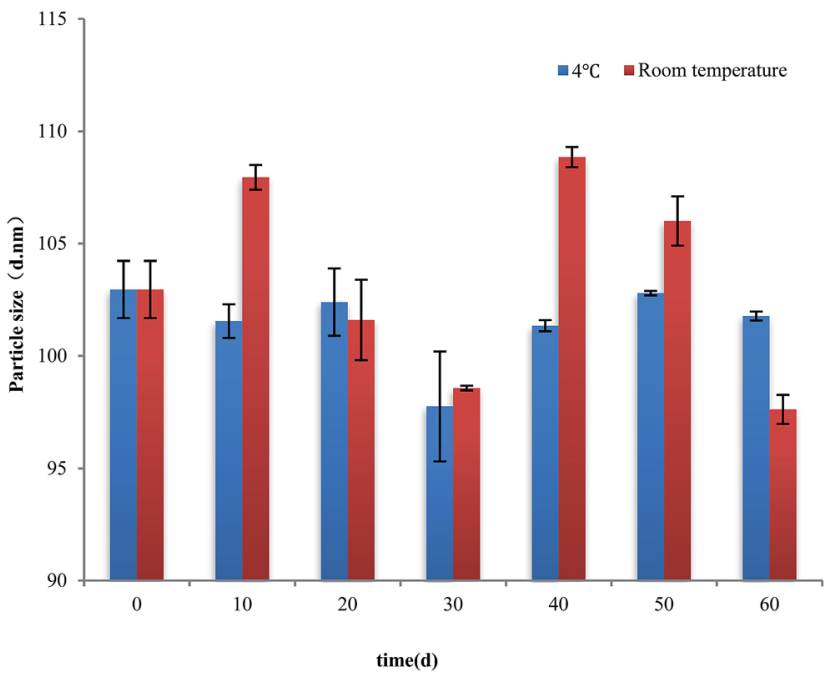

Fig. 7 Particle size of PPI nanoparticles during 60 days storage at $4{ }^{\circ} \mathrm{C}$ and room temperature.

the PPI nanoparticles at $4{ }^{\circ} \mathrm{C}$ was better than that of the stability at room temperature. This proved that the PPI nanoparticles had good storage stability, and showed higher practical application value in the future (Fig. 7).

\section{Conclusion}

In conclusion, the nanoparticles were successfully synthesized with peanut protein isolate through calcium ion induction. PPI nanoparticle so produced displayed nano scale $(80 \mathrm{~nm}$ to $140 \mathrm{~nm}$ ), good sphericity in shape and comparatively uniform size distribution $(<0.500)$. This study also demonstrated that alkaline and heat treatment was necessary for the fully hydrated and denaturation (loss quaternary structure) of peanut protein isolate which could benefit to calcium ion induction and stable structure of PPI nanoparticles. Besides, after dry processing, PPI nanoparticles still present a good condition and the properties of the nanoparticles treated by the spray drying process is superior to that vacuum freeze drying. We also found that PPI nanoparticles have good thermal stability, dilution stability and storage stability. This make them suitable as bioactive compound carries in food industry to enhance their bioavailability.

\section{Conflicts of interest}

There are no conflicts to declare.

\section{Acknowledgements}

The authors gratefully acknowledge the technical assistance of Key Laboratory of Agro-Products Processing, Ministry of Agriculture and for allowing the authors to use the necessary instruments. This work is supported by the projects as followed: The National Key Research and Development Plan (2016YFD0400205), The National Science Foundation of China
(31701545), Science and Technology Innovation Project of Chinese Academy of Agricultural Sciences.

\section{References}

1 Z. Li, H. Jiang, C. Xu, et al., A review: using nanoparticles to enhance absorption and bioavailability of phenolic phytochemicals, Food Hydrocolloids, 2015, 43, 153-164.

2 M. A. Shahbazi, P. V. Almeida, A. Correia, et al., Intracellular responsive dual delivery by endosomolytic polyplexes carrying DNA anchored porous silicon nanoparticles, $J$. Controlled Release, 2017, 249, 111-122.

3 M. Marciello, S. Rossi, C. Caramella, et al., Freeze-dried cylinders carrying chitosan nanoparticles for vaginal peptide delivery, Carbohydr. Polym., 2017, 170, 43-51.

4 N. Levi-Polyachenko, R. Jacob, C. Day, et al., Chitosan wound dressing with hexagonal silver nanoparticles for hyperthermia and enhanced delivery of small molecules, Colloids Surf., B, 2016, 142, 315.

5 P. Fonte, F. Araújo, C. Silva, et al., Polymer-based nanoparticles for oral insulin delivery: revisited approaches, Biotechnol. Adv., 2015, 33(6), 1342.

6 S. Sundar, J. Kundu and S. C. Kundu, Topical review: biopolymeric nanoparticles, Sci. Technol. Adv. Mater., 2010, 11, 1-13.

7 F. Mottaghitalab, M. Farokhi, M. A. Shokrgozar, et al., Silk fibroin nanoparticle as a novel drug delivery system, $J$. Controlled Release, 2015, 206, 161.

8 M. Jahanshahi and Z. Babaei, Protein nanoparticle: a unique system as drug delivery vehicles, Afr. J. Biotechnol., 2008, $7(25), 4926-4934$.

9 F. Chen, J. Wu, C. Zheng, et al., TPGS modified reduced bovine serum albumin nanoparticles as a lipophilic anticancer drug carrier for overcoming multidrug resistance, J. Mater. Chem. B, 2016, 4(22), 3959-3968.

10 J. Y. Jun, H. H. Nguyen, H. S. Chun, et al., Preparation of sizecontrolled bovine serum albumin (BSA) nanoparticles by a modified desolvation method, Food Chem., 2011, 127(4), 1892-1898.

11 A. O. Elzoghby, W. M. Samy and N. A. Elgindy, Novel spraydried genipin-crosslinked casein nanoparticles for prolonged release of alfuzosin hydrochloride, Pharm. Res., 2013, 30(2), 512-522.

12 R. Penalva, I. Esparza, M. Agüeros, et al., Casein nanoparticles as carriers for the oral delivery of folic acid, Food Hydrocolloids, 2015, 44, 399-406.

13 M. Papi, V. Palmieri, G. Maulucci, et al., Controlled self assembly of collagen nanoparticle, J. Nanopart. Res., 2011, 13(11), 6141-6147.

14 B. Ghalandari, A. Divsalar, A. A. Saboury, et al., $\beta$ Lactoglobulin nanoparticle as a chemotherapy agent carrier for oral drug delivery system, J. Iran. Chem. Soc., 2015, 12(4), 613-619.

15 H. K. Ha, J. W. Kim, M. R. Lee, et al., Cellular Uptake and Cytotoxicity of $\beta$-Lactoglobulin Nanoparticles: the Effects of Particle Size and Surface Charge, Asian-Australas. J. Anim. Sci., 2015, 28(3), 420. 
16 J. Wu, M. Shi, W. Li, et al., Pickering emulsions stabilized by whey protein nanoparticles prepared by thermal crosslinking, Colloids Surf., B, 2015, 127, 96-104.

17 Z. Fereshteh, M. Fathi, A. Bagri, et al., Preparation and characterization of aligned porous PCL/zein scaffolds as drug delivery systems via improved unidirectional freezedrying method, Mater. Sci. Eng., C, 2016, 613-622.

18 J. Zhang, L. Liang, Z. Tian, et al., Preparation and in vitro, evaluation of calcium-induced soy protein isolate nanoparticles and their formation mechanism study, Food Chem., 2012, 133(2), 390-399.

19 Q. Wang, Peanuts: Processing Technology and Product Development, Academic Press, 2016.

20 C. Park, C. L. Vo, T. Kang, et al., New method and characterization of self-assembled gelatin-oleic nanoparticles using a desolvation method via carbodiimide/ $N$-hydroxysuccinimide (EDC/NHS) reaction, Eur. J. Pharm. Biopharm., 2015, 89, 365.

21 Q. Sun, G. Li, L. Dai, et al., Green preparation and characterisation of waxy maize starch nanoparticles through enzymolysis and recrystallisation, Food Chem., 2014, 162(11), 223-228.

22 L. Battaglia, M. Gallarate, E. Peira, et al., Bevacizumab loaded solid lipid nanoparticles prepared by the coacervation technique: preliminary in vitro studies, Nanotechnology, 2015, 26(25), 255102.

23 S. A. Fioramonti, A. A. Perez, E. E. Aríngoli, et al., Design and characterization of soluble biopolymer complexes produced by electrostatic self-assembly of a whey protein isolate and sodium alginate, Food Hydrocolloids, 2014, 35(1), 129-136.

24 A. M. Shi, D. Li, L. J. Wang, et al., Preparation of starch-based nanoparticles through high-pressure homogenization and miniemulsion cross-linking: influence of various process parameters on particle size and stability, Carbohydr. Polym., 2011, 83(4), 1604-1610.

25 N. Stănciuc, I. Banu, C. Bolea, et al., Structural and antigenic properties of thermally treated gluten proteins, Food Chem., 2017, DOI: 10.1016/j.foodchem.2017.03.018.

26 Z. Chen, J. Li, Y. Tu, et al., Changes in gel characteristics of egg white under strong alkali treatment, Food Hydrocolloids, 2015, 45, 1-8.

27 Y. Liu, G. Zhao, J. Ren, et al., Effect of denaturation during extraction on the conformational and functional properties of peanut protein isolate, Innovative Food Sci. Emerging Technol., 2011, 12(3), 375-380.
28 F. Hou, W. Ding, W. Qu, et al., Alkali solution extraction of rice residue protein isolates: influence of alkali concentration on protein functional, structural properties and lysinoalanine formation, Food Chem., 2017, 218, 207215.

29 N. Murekatete, Y. Hua, O. Djakpo, et al., Gelation Behavior and Rheological Properties of Salt- or Acid-Induced Soy Proteins Soft Tofu-Type Gels, J. Texture Stud., 2014, 45(1), 62-73.

30 J. Beirowski, S. Inghelbrecht, A. Arien, et al., Freeze-drying of nanosuspensions, 1: freezing rate versus formulation design as critical factors to preserve the original particle size distribution, J. Pharm. Sci., 2011, 100(5), 1958-1968.

31 R. P. Patel, M. P. Patel and A. M. Suthar, Spray drying technology: an overview, Indian J. Sci. Technol., 2009, 2(10), 44-47.

32 V. V. Patil, P. P. Dandekar, V. B. Patravale, et al., Freeze drying: potential for powdered nanoparticulate product, Drying Technol., 2010, 28(5), 624-635.

33 A. M. Shi, L. J. Wang, D. Li, et al., The effect of annealing and cryoprotectants on the properties of vacuum-freeze dried starch nanoparticles, Carbohydr. Polym., 2012, 88(4), 13341341.

34 A. Gharsallaoui, G. Roudaut, O. Chambin, et al., Applications of spray-drying in microencapsulation of food ingredients: an overview, Food Res. Int., 2007, 40(9), 11071121.

35 T. W. Wong and P. John, Advances in Spray Drying Technology for Nanoparticle Formation, Springer International Publishing, 2016.

36 I. Gülseren, Y. Fang and M. Corredig, Whey protein nanoparticles prepared with desolvation with ethanol: characterization, thermal stability and interfacial behavior, Food Hydrocolloids, 2012, 29(2), 258-264.

37 Z. Mou-Ming, Y. Bo-En, L. Dong-Hui, et al., Subunit Dissociation of Soybean Protein Isolates in Acid Conditions, J. South China Univ. Technol., Nat. Sci., 2011, 39(9), 22-27.

38 W. Su-Jun, L. Yan-Feng, Z. Yin-Xing, et al., Dodecanoled$\operatorname{poly}(D, L$-lactic acid)- $b$-poly(ethylene glycol)-folate (Dol-PLAPEG-FA): the study of dilution stability and targeting selectivity against different cells, Funct. Mater., 2012, 19(43), 2642-2646. 